\title{
In silico prediction of Gallibacterium anatis pan-immunogens
}

\author{
Ragnhild J Bager ${ }^{1}$, Egle Kudirkiene ${ }^{1}$, Isabelle da Piedade ${ }^{1}$, Torsten Seemann² ${ }^{2}$ Tine K Nielsen ${ }^{3}$, Susanne E Pors ${ }^{1}$, \\ Andreas $\mathrm{H}$ Mattsson ${ }^{4,5}$, John D Boyce ${ }^{6}$, Ben Adler ${ }^{7}$ and Anders M Bojesen ${ }^{1 *}$
}

\begin{abstract}
The Gram-negative bacterium Gallibacterium anatis is a major cause of salpingitis and peritonitis in commercial egg-layers, leading to reduced egg production and increased mortality. Unfortunately, widespread multidrug resistance and antigenic diversity makes it difficult to control infections and novel prevention strategies are urgently needed. In this study, a pan-genomic reverse vaccinology (RV) approach was used to identify potential vaccine candidates. Firstly, the genomes of 10 selected Gallibacterium strains were analyzed and proteins selected on the following criteria; predicted surface-exposure or secretion, none or one transmembrane helix (TMH), and presence in six or more of the 10 genomes. In total, 42 proteins were selected. The genes encoding 27 of these proteins were successfully cloned in Escherichia coli and the proteins expressed and purified. To reduce the number of vaccine candidates for in vivo testing, each of the purified recombinant proteins was screened by ELISA for their ability to elicit a significant serological response with serum from chickens that had been infected with $G$. anatis. Additionally, an in silico prediction of the protective potential was carried out based on a protein property prediction method. Of the 27 proteins, two novel putative immunogens were identified; Gab_1309 and Gab_2312. Moreover, three previously characterized virulence factors; GtxA, FlfA and Gab_2156, were identified. Thus, by combining the pan-genomic RV approach with subsequent in vitro and in silico screening, we have narrowed down the pan-proteome of $G$. anatis to five vaccine candidates. Importantly, preliminary immunization trials indicated an in vivo protective potential of GtxA-N, FlfA and Gab_1309.
\end{abstract}

\section{Introduction}

Poultry meat and eggs are considered very important and sustainable sources of animal protein worldwide [1], making efficient strategies to prevent and control the spread of poultry diseases highly important [2]. Gallibacterium anatis is a Gram-negative, non-motile, encapsulated coccobacillus of the Pasteurellaceae family [3,4] and commonly associated with poultry [5]. Besides constituting a part of the normal microflora of the upper respiratory tract and lower genital tract in chickens [6], it is also considered a major cause of salpingitis and peritonitis in egg-laying chickens [7-9]. Thus, G. anatis infections lead to a drop in egg production and increased mortality in commercial layers [10]. Unfortunately, widespread multiple-drug resistance [11] hinders treatment with traditional antimicrobial agents, while substantial

\footnotetext{
* Correspondence: miki@sund.ku.dk

${ }^{1}$ Department of Veterinary Disease Biology, Faculty of Health and Medical Sciences, University of Copenhagen, 1870 Frederiksberg C, Denmark Full list of author information is available at the end of the article
}

antigenic diversity [12] among disease-causing field isolates hampers disease prevention by classical vaccination with inactivated whole cell bacterins. Hence, novel prevention strategies are urgently needed.

The sequencing of the first bacterial genome in 1995 [13] initiated the genomic era and catalyzed a shift from conventional culture-based approaches to genome-based vaccinology [14]. This gave rise to the Reverse Vaccinology (RV) approach [15], in which bioinformatics tools are used to analyze genome sequences to identify genes encoding likely protective antigens. The concept of RV was initially applied to Neisseria meningitidis serogroup B (MenB) [16], for which conventional vaccine development approaches had failed in producing an efficacious vaccine. Based on the genomic sequence of MenB strain MC58 [17], five universal vaccine candidates were identified [18], and the resulting $4 \mathrm{CMenB}$ vaccine (Bexsero ${ }^{\circ}$ ) is now approved in the EU for active immunization of individuals aged over two months against disease caused 
by MenB [19]. Since this pioneering MenB project, the $\mathrm{RV}$ approach has been applied to a variety of other important pathogens [20]. However, the increased availability of multiple genomes for the same bacterial species has shown that genomic variability in bacteria is much more extensive than initially anticipated. Thus, analysis of the genome of a single strain often fails to address intra-species genetic variability and limits the effectiveness of genome-wide screens for vaccine candidates. To overcome this, a pan-genomic RV model utilizing the global gene repertoire for a species was proposed by Tettelin et al. [21]. Pan-genomic RV was first applied to vaccine development in Group B Streptococcus [22], and this study demonstrated the importance of sequencing multiple strains of a single pathogen for the identification of vaccine antigens [23]. The application of in silico and in vitro predictions has not only enabled a much more rational selection of vaccine candidates, but has also shown promise at reducing the number of experimental animals needed to verify the effectiveness of vaccine candidates.

We report here the use of a pan-genomic RV approach for identification of novel and conserved immunogens of G. anatis. By implementing different in silico approaches and in vitro assays, we screened the Gallibacterium panproteome, resulting in a final selection of five proteins with a high predicted potential as vaccine candidates. Importantly, preliminary in vitro immunization results indicate protective potential of at least three of these candidates including FlfA, which has previously been tested and confirmed highly protective against homologous challenge in chickens [24]. Together, these results provide an important step in the development of a new and broadly protective vaccine against $G$. anatis.

\section{Materials and methods}

Animal ethics statement

All work on experimental animals was carried out with the approval of the Danish National Animal Ethics Committee (Approval no. 2012-15-2934-00339 and 2012-15-293400923).

\section{Gallibacterium strains and growth conditions}

The 10 Gallibacterium strains included in the study are listed in Table 1. The strains were selected based on their pathogenic potential, prevalence in the field and genetic diversity, in order to provide as much diversity as possible within the species. Bacteria were incubated at $37^{\circ} \mathrm{C}$ on brain heart infusion (BHI) agar supplemented with $5 \%$ citrated bovine blood in a closed plastic bag or in BHI broth with aeration.

\section{$\mathrm{RV}$ in silico analysis}

Sequencing and assembly of G. anatis strains 12656-12 and $\mathrm{F} 149^{\mathrm{T}}$ was performed as described previously [27]. The remaining genomes were sequenced using the Illumina Genome Analyzer IIx (CD genomics, New York, USA). Reads were assembled using VelvetOptimiser 2.0 [28]. All 10 genomes were annotated using Prokka v.1.0 [29]. The subcellular localization of the 31564 annotated proteins from the 10 genomes was predicted using standalone PSORTb v.3.0 [30]. The presence of $\mathrm{N}$ terminal signal peptides was predicted using SignalP

Table 1 Gallibacterium strains for included in this study

\begin{tabular}{|c|c|c|c|c|c|}
\hline Strain & Biovar & Host/tissue & Lesions & Country $^{a}$ & Reference \\
\hline \multicolumn{6}{|l|}{ G. anatis bv. anatis } \\
\hline \multicolumn{6}{|l|}{ Biovar anatis } \\
\hline $\mathrm{F} 149^{\top}$ & NA & Duck/intestine & - & DK & [3] \\
\hline \multicolumn{6}{|c|}{ Biovar haemolytica } \\
\hline $12656-12$ & 4 & Chicken/liver & + & DK & {$[25]$} \\
\hline $10672-6$ & 1 & Chicken/oviduct & + & DK & [3] \\
\hline 4895 & 4 & Chicken/NA & + & $M X$ & {$[26]$} \\
\hline 7990 & 3 & Chicken/NA & + & $M X$ & {$[26]$} \\
\hline Avicor & 4 & Chicken/heart & + & $M X$ & {$[26]$} \\
\hline CCM5995 & 20 & Chicken/NA & NA & $\mathrm{Cz}$ & [3] \\
\hline IPDH 697-78 & 15 & Chicken/NA & + & G & [3] \\
\hline \multicolumn{6}{|c|}{ G. genomospecies 1} \\
\hline CCM5974 & 8 & Hen/Liver & + & $\mathrm{Cz}$ & {$[3]$} \\
\hline \multicolumn{6}{|c|}{ G. genomospecies 2} \\
\hline CCM5976 & 9 & Hen/oviduct & + & $\mathrm{Cz}$ & [3] \\
\hline
\end{tabular}

${ }^{a}$ Cz: Czech Republic, DK: Denmark, G: Germany, MX: Mexico.

${ }^{\mathrm{T}}=$ type strain.

$\mathrm{NA}=$ Not available. 
v.3.0 [31] and the number of transmembrane helices (TMHs) was predicted by TMHMM v.2.0 [32]. The protein conservation among the strains was analyzed using BLASTp v.2.2.22 [33] with default parameters. The theoretical molecular masses and isoelectric points were calculated using the pepstats tool in EMBOSS [34]. In total, 42 proteins were selected (Table 2).

\section{Cloning and small-scale protein expression}

Each of the selected genes was amplified from the $G$. anatis 12656-12 genome by PCR and cloned into the Gateway entry vector $\mathrm{pENTR}{ }^{\mathrm{Tm}} / \mathrm{SD} / \mathrm{D}-\mathrm{TOPO}$ (Invitrogen). Primers were designed using Oligo Explorer 1.2 (Gene Link $^{\text {tix }}$, Hawthorne, NY, USA) as described previously [37]. Areas with high predicted hydrophobicity in the $\mathrm{N}$ and/or $\mathrm{C}$ terminus were removed, as were predicted signal peptides. In addition, GtxA was cloned as two parts $(\mathrm{N}$ - and C-terminal) due to its size. The E. coli strains and plasmids used in this study are listed in Additional file 1. Genes were cloned and small-scale expressed as described in Additional file 2 using Gateway cloning and ligationindependent cloning (LIC) systems. Altogether, 37 expression clones were constructed for 36 of the 42 selected proteins (two clones were made for GtxA). The primer sequences used for gene amplification, and the final expression vector chosen for protein expression from each gene, are listed in Additional file 3.

\section{Large-scale protein expression and purification}

All proteins were expressed and purified in large-scale from E. coli Rosetta 2 (DE3) cells (Novagen, Madison, WI, USA). Large-scale expression was performed in a custommade large-scale expression system (LEX) (Harbinger Biotech, Toronto, Canada) as described previously [38] and in Additional file 2. Of the 37 expression clones, 27 recombinant proteins were successfully purified; the majority (17) of these proteins had a purity $>90 \%$.

\section{Production of antiserum against G. anatis 12656-12 in chickens}

Two Lohmann brown chickens (21 weeks old) were purchased from a commercial breeder with high biosecurity standards. The chickens were kept under free indoor housing conditions and were provided with fresh water and feed ad libitum. The chickens were swabbed for the presence of G. anatis by a cloacal swab. After two weeks of acclimatization the chickens were challenged with $10^{5}$ colony forming units (CFU) of G. anatis $12656-12$ by injection into the peritoneal cavity as previously described [39] and re-infected 2 weeks after the first infection. Blood for serum purification was collected from the brachial vein prior to the first infection (pre-immune antiserum) and one week after the second infection (hyper-immune antiserum).

\section{Enzyme-Linked Immunosorbent Assay (ELISA)}

The putative immunogenicity of each of the purified recombinant proteins was assessed by indirect ELISA as described previously [40], using pooled anti-G. anatis pre-immune and hyper-immune antiserum. Briefly, NuncImmuno $^{\text {Tw }}$ MicroWell $^{\text {Tw }}$ 96-Well Plates (Thermo Scientific, Waltham, MA, USA) were coated overnight at $4{ }^{\circ} \mathrm{C}$ with $0.5 \mu \mathrm{g}$ recombinant protein (48 wells per protein) diluted in carbonate-bicarbonate buffer ( $\mathrm{pH}$ 9.6) (Sigma-Aldrich, St. Louis, MO, USA). Each well was then washed; this and all subsequent washing steps consisted of three washes in $350 \mu \mathrm{L}$ wash buffer (PBS $+0.05 \%$ Tween 20$)$. The wells were blocked for $2 \mathrm{~h}$ at room temperature in $200 \mu \mathrm{L}$ blocking solution (PBS containing $0.05 \%$ Tween 20 and $2 \%$ bovine serum albumin (BSA)) and washed. The antibody titers were assayed by serial 3-fold dilutions of chicken serum ranging from 1:200 to 1:48600. All dilutions were prepared in triplicate in dilution buffer (PBS containing $0.05 \%$ Tween 20 and $0.1 \%$ BSA), $100 \mu \mathrm{L}$ were added to each well and plates were incubated for $1 \mathrm{~h}$ at $37{ }^{\circ} \mathrm{C}$. For each assay, 12 control wells were included, which contained pure dilution buffer; secondary antibody was added to 6 of these wells as a measure of background, and the other 6 wells remained blank as a negative control for the ELISA. Following incubation, the wells were washed and $100 \mu \mathrm{L}$ polyclonal goat anti-chicken IgG (Fc): HRP (AbD Serotec, Puchheim, Germany), diluted 1:4000 in diluting buffer, were added to each well and the plates incubated for a further $1 \mathrm{~h}$ at $37^{\circ} \mathrm{C}$ and then washed. To detect the binding, $100 \mu \mathrm{L}$ of 3,3',5,5' -Tetramethylbenzidine (TMB) liquid substrate (Sigma) were added to each well. The plates were incubated for $2 \mathrm{~min}$ and then the reaction was stopped by addition of $100 \mu \mathrm{L} 1 \mathrm{M} \mathrm{HCl}$. The absorbance was read immediately at $450 \mathrm{~nm}$ in a PowerWave XS spectrophotometry (BioTek Instruments, Winooski, VT, USA).

The antibody titers were calculated for the measured absorbances at $450 \mathrm{~nm}$ [41], using the "Antibody Titers" online data analysis tool [42]. To compare and rank the ELISA results, a $\mathrm{P} / \mathrm{N}$ ratio $(\mathrm{P}=$ hyper-immune serum, $\mathrm{N}=$ pre-immune serum) of mean antibody titers was calculated [43]. All statistical analysis was performed using SAS version 9.3 (SAS Institute, Cary, NC, USA), and differences between groups assessed using a one-way t-test. The recognition of recombinant protein by hyper-immune serum was deemed significant at $P<0.05$, indicating that the protein was expressed in vivo during $G$. anatis infection and elicited a specific immune response.

\section{VacFinder ${ }^{\circledR}$ in silico protein analysis}

To further predict the protective potential of each of the expressed proteins, each of the proteins was analyzed using the proprietary VacFinder ${ }^{\circ}$ in silico technology platform (Evaxion Biotech, LLC, USA). VacFinder ${ }^{\circ}$ is a 
Table 2 The 42 proteins from G. anatis 12656-12 selected for cloning and expression

\begin{tabular}{|c|c|c|c|c|c|c|}
\hline Protein ID & Description & $\mathrm{Mw}(\mathrm{kDa})$ & PSORTb prediction & $\begin{array}{l}\text { TMHMM } \\
\text { prediction }\end{array}$ & $\begin{array}{l}\text { SignalP } \\
\text { prediction }\end{array}$ & Acc. no. \\
\hline Gab_0001 & Hypothetical protein & 195.9 & Outer membrane & 0 & No & ERF78007.1 \\
\hline Gab_0047 & $\begin{array}{l}\text { Metal-dependent proteases with possible } \\
\text { chaperone activity }\end{array}$ & 36.5 & Extracellular & 0 & No & ERF77629.1 \\
\hline Gab_0087 & Hypothetical protein & 140.9 & Extracellular & 0 & No & ERF78219.1 \\
\hline Gab_0091 & Outer membrane lipoprotein & 15.3 & Unknown & 0 & Yes & ERF79624.1 \\
\hline Gab_0151 ${ }^{a}$ & $\begin{array}{l}\text { RTX toxins and related } \\
\text { Ca2 }+ \text {-binding proteins }\end{array}$ & 216.4 & Extracellular & 0 & No & FJ917356 \\
\hline Gab_0178 & Predicted secreted acid phosphatase & 30.5 & Unknown & 0 & Yes & ERF78374.1 \\
\hline Gab_0186 & $\begin{array}{l}\text { Membrane-bound lytic } \\
\text { murein transglycosylase }\end{array}$ & 39.9 & Unknown & 0 & Yes & ERF78366.1 \\
\hline Gab_0337 & Autotransporter adhesin & 142.3 & Extracellular & 0 & No & ERF78595.1 \\
\hline Gab_0523 & $\begin{array}{l}\text { Outer membrane protein and related } \\
\text { peptidoglycan-associated (lipo)proteins }\end{array}$ & 16.4 & Outer membrane & 0 & Yes & ERF78926.1 \\
\hline Gab_0572b & F17-like fimbrial subunit & 19.1 & Extracellular & 0 & Yes & ERF79277.1 \\
\hline Gab_0574 & P pilus assembly protein, porin PapC & 94.2 & Outer membrane & 0 & Yes & ERF79276.1 \\
\hline Gab_0602 & Outer membrane protein & 47.8 & Outer membrane & 0 & Yes & ERF78505.1 \\
\hline Gab_0652 & Organic solvent tolerance protein OstA & 90.1 & Outer membrane & 0 & Yes & ERF78644.1 \\
\hline Gab_0661 & Small protein A (tmRNA-binding) & 16 & Unknown & 0 & Yes & ERF78651.1 \\
\hline Gab_0925 & Hypothetical protein & 85.2 & $\begin{array}{l}\text { Outer membrane } \\
\text { and/or extracellular }\end{array}$ & 0 & Yes & ERF77284.1 \\
\hline Gab_0999 & Rare lipoprotein B & 18.2 & Unknown & 1 & Yes & ERF79357.1 \\
\hline Gab_1008 & Type II secretory pathway, component HofQ & 42.1 & Outer membrane & 0 & No & ERF79423.1 \\
\hline Gab_1162 & P pilus assembly protein, porin PapC & 93.8 & Outer membrane & 0 & Yes & ERF78846.1 \\
\hline Gab_1164 & F17-like fimbrial subunit & 20.5 & Extracellular & 0 & Yes & JX855927 \\
\hline Gab_1192 & Surface lipoprotein & 28 & Cytoplasmic membrane & 0 & Yes & ERF78832.1 \\
\hline Gab_1245 & Hemolysin activation/secretion protein & 67.8 & Outer membrane & 1 & Yes & ERF78979.1 \\
\hline Gab_1283 & Long-chain fatty acid transport protein & 48.8 & Outer membrane & 0 & Yes & ERF77302.1 \\
\hline Gab_1309 & Membrane proteins related to metalloendopeptidases & 42.7 & Unknown & 0 & Yes & ERF77527.1 \\
\hline Gab_1396 & Uncharacterized protein conserved in bacteria & 146.6 & Outer membrane & 1 & No & ERF79175.1 \\
\hline Gab_1397 & Outer membrane protein & 65.9 & Outer membrane & 0 & Yes & ERF79124.1 \\
\hline Gab_1399 & Membrane-bound metallopeptidase & 47.2 & $\begin{array}{l}\text { Outer membrane } \\
\text { and/or extracellular }\end{array}$ & 0 & Yes & ERF79126.1 \\
\hline Gab_1450 & Opacity protein and related surface antigens & 23.1 & Outer membrane & 1 & Yes & ERF79004.1 \\
\hline Gab_1576 & $\begin{array}{l}\text { Outer membrane receptor for ferrienterochelin } \\
\text { and colicins }\end{array}$ & 23.4 & Outer membrane & 0 & No & ERF78509.1 \\
\hline Gab_1631 & Cell envelope opacity-associated protein A & 43.9 & Extracellular & 1 & No & ERF79417.1 \\
\hline Gab_1654 & Outer membrane phospholipase A & 32.4 & Outer membrane & 1 & Yes & ERF79322.1 \\
\hline Gab_1755 & $\begin{array}{l}\text { Outer membrane protein and related } \\
\text { peptidoglycan-associated (lipo)proteins }\end{array}$ & 27.9 & Outer membrane & 0 & Yes & ERF79542.1 \\
\hline Gab_2087 & Outer membrane protein & 51 & Outer membrane & 0 & Yes & ERF78059.1 \\
\hline Gab_2124c & Outer membrane protein (porin) & 41.1 & Outer membrane & 0 & Yes & KF160335 \\
\hline Gab_2156 ${ }^{b}$ & F17-like fimbrial subunit & 20.7 & Extracellular & 0 & Yes & ERF79559.1 \\
\hline Gab_2158 & P pilus assembly protein, porin PapC & 90.6 & Outer membrane & 0 & Yes & ERF79560.1 \\
\hline Gab_2192 & Outer membrane protein $\mathrm{W}$ & 25.7 & Outer membrane & 0 & Yes & ERF78317.1 \\
\hline Gab_2224 & Outer membrane receptor proteins, & 81 & Outer membrane & 0 & Yes & ERF78217.1 \\
\hline
\end{tabular}


Table 2 The 42 proteins from G. anatis 12656-12 selected for cloning and expression (Continued)

\begin{tabular}{|c|c|c|c|c|c|c|}
\hline Gab_2274 & $\begin{array}{l}\text { Outer membrane receptor proteins, } \\
\text { mostly Fe transport }\end{array}$ & 74 & Outer membrane & 0 & Yes & ERF77464.1 \\
\hline Gab_2304 & Glycerophosphoryl diester phosphodiesterase & 41.6 & Unknown & 0 & Yes & ERF77421.1 \\
\hline Gab_2312 & Autotransporter adhesin & 325.7 & $\begin{array}{l}\text { Outer membrane } \\
\text { and/or extracellular }\end{array}$ & 0 & No & ERF77433.1 \\
\hline Gab_2347 & $\begin{array}{l}\text { Outer membrane protein/protective } \\
\text { antigen OMA87 }\end{array}$ & 89.3 & Outer membrane & 0 & Yes & ERF79042.1 \\
\hline Gab_2348 & Outer membrane protein & 19.8 & Outer membrane & 0 & Yes & ERF79081.1 \\
\hline
\end{tabular}

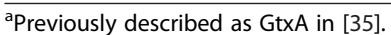

bPreviously described in [24]. Gab_1164 = FlfA.

'Previously described as OmpC in [36].

data-driven machine learning method trained by protein property pattern recognition on known and protective B-cell protein antigens (except for exotoxins), aiming at identifying novel and protective B-cell protein antigens with a neutralizing opsonizing profile. The machinelearned prediction is based on specific protein property features of protein sequences rather than sequence similarity, allowing antigen classification based solely on protein properties [44]. The output is a list of proteins from the proteome ranked by their ability to elicit a highly protective antibody response.

\section{Immunization of layer chickens with recombinant proteins}

24 Isa Brown layer chickens (16 weeks old) were purchased from a commercial breeder with high biosecurity standards. The chickens were swabbed for the presence of $G$. anatis by a cloacal swab. The chickens were randomly divided in eight groups of four each and allowed to acclimatize for one week after arrival. The chickens were kept under free indoor housing conditions and provided with fresh water and feed ad libitum. Each group was immunized subcutaneously with $100 \mu \mathrm{g}$ of one of the five selected recombinant proteins (GtxA-N, FlfA, Gab_1309, Gab_2156 or Gab_2312) mixed in $0.5 \mathrm{~mL}$ of SEC buffer (50 mM NaP, $150 \mathrm{mM} \mathrm{NaCl}, 0.5 \mathrm{mM}$ TCEP, $10 \%$ glycerol; pH 7.5) and $0.5 \mathrm{~mL}$ of Freund's incomplete adjuvant (Sigma-Aldrich). As a control (non-immunized), a group of four chickens was immunized with a placebo (SEC buffer and Freund's incomplete adjuvant). Two weeks after the immunization all chickens were infected intraperitoneally with $1.5 \times 10^{6} \mathrm{CFU}$ of G. anatis 1265612 as described previously [39]. Forty-eight hours after infection the chickens were euthanized and a post mortem examination was conducted. To assess the protective effect of the immunization, the lesions found in peritoneum of each bird were scored according to three parameters: (i) inflammatory reaction, (ii) amount of exudate, and (iii) clarity of the peritoneal surfaces. All parameters were scored on a scale from $0-3$, thus giving a maximum score of 9. Furthermore, the presence of Gallibacterium was detected by swabbing the peritoneum with a sterile cotton swab and streaking it onto BHI blood agar. The scorings of the lesions in the peritoneum were analyzed by a Mann Whitney $\mathrm{U}$ test and $P<0.05$ were deemed significant.

\section{Multiple sequence alignments}

Multiple amino acid sequence alignments of the Gab_1309 and Gab_2312 proteins and their orthologs were prepared using MAFFT v7.130b [45] and formatted using Jalview 2.8.0b1 [46].

\section{Genbank accession numbers}

The genome sequence of $G$. anatis 12656-12 has recently been made available [47] and was submitted to Genbank (BioProject ID: 213810, accession number AVOX00000000). The nucleotide sequence accession numbers for the genes included in this study are listed in Table 2. Genome sequence reads from the nine Gallibacterium strains used for Gab 1309 and Gab_2312 multiple sequence alignment were submitted to the NCBI Sequence Read Archive (SRA) [48] and can be retrieved using the study accession number SRP029613.

\section{Results}

$\mathrm{RV}$ in silico prediction of candidate vaccine antigens

For the identification and selection of putative immunogens, the genomes of 10 Gallibacterium strains were analyzed (Table 1). Based on the central premise that protective antigens should be accessible to the host immune system, proteins predicted to be surface-exposed or secreted were selected from the G. anatis pan-proteome. Moreover, proteins with more than one TMH were discarded, based on the premise that they are unlikely to be transported beyond the inner membrane. In addition, these proteins have the highest rate of expression failure during subsequent procedures [16] or are less likely to be over-expressed in E. coli [49]. Finally, proteins present in six or more of the $10 \mathrm{G}$. anatis genomes were identified. A protein was considered present if a significant full length match $\left(\mathrm{E}\right.$-value $<10^{-8}$ ) was obtained. From a total of 31564 proteins, 162 proteins were predicted as extracellular proteins and 482 proteins as 
outer membrane proteins. Of these, 42 proteins were present in six or more of the 10 genomes and these proteins were selected for further studies (Table 2).

\section{Cloning, expression and purification}

Each of the 42 selected genes was amplified from the $G$. anatis strain 12656-12 genome by PCR. This strain was chosen for gene cloning as it is a well-characterized and highly pathogenic strain originally isolated from the liver of a chicken with septicaemia [25,39]. Using different high-throughput cloning strategies, 37 proteins were successfully purified at a small-scale from $E$. coli and of these, 27 were successfully purified in the large-scale trials (Table 3). The 10 remaining proteins were lost during the large-scale purification process due to low yield, impurities or lack of expression in E. coli in large-scale cultures.

\section{Screening of immunogenic potential by ELISA}

In order to reduce the number of antigens to be tested in vaccine trials, the immunogenic potential of the 27 purified proteins was assessed in vitro by an indirect ELISA approach using pools of anti-G. anatis 12656-12 pre-immune and hyper-immune antiserum from two chickens. The chickens were, as expected, found to be positive for G. anatis on the cloacal mucosa prior to the immunizations. The mean antibody titers were calculated for each protein using both pre-immune and hyper-immune antiserum. To rank the proteins, $\mathrm{P} / \mathrm{N}$ values between the two antibody titers were calculated

Table 3 The 27 large-scale purified proteins

\begin{tabular}{|c|c|c|c|c|}
\hline Protein ID & Description & Form & $\mathrm{P} / \mathrm{N}$ ratio $^{\mathrm{a}}$ & Acc. no. \\
\hline GtxA-N ${ }^{c}$ & RTX toxin (first half part) & Soluble & $20.1^{* * *}$ & FJ917356 \\
\hline Gab_0523 & Outer membrane protein and related peptidoglycan-associated (lipo)proteins & Soluble & $7.9^{* * *}$ & ERF78926.1 \\
\hline Gab_2156 & F17-like fimbrial subunit & Soluble & $6.6^{* * *}$ & ERF79559.1 \\
\hline Gab_0091 & Outer membrane lipoprotein & Insoluble & $5.9^{* * *}$ & ERF79624.1 \\
\hline Gab_2348 & Outer membrane protein & Insoluble & $4.1^{* * *}$ & ERF79081.1 \\
\hline FlfA $^{d}$ & F17-like fimbrial subunit & Soluble & $2.5^{* * *}$ & JX855927 \\
\hline Gab_1755 & Outer membrane protein and related peptidoglycan-associated (lipo)proteins & Insoluble & $1.8^{* * *}$ & ERF79542.1 \\
\hline Gab_1309 & Membrane proteins related to metalloendopeptidases & Soluble & $1.7^{* * * b}$ & ERF77527.1 \\
\hline Gab_2312 & Autotransporter adhesion & Soluble & $1.7^{* * * b}$ & ERF77433.1 \\
\hline GtxA-C & RTX toxin (last half part) & Insoluble & $1.4^{* * *}$ & FJ917356 \\
\hline Gab_1576 & Outer membrane receptor for ferrienterochelin and colicins & Insoluble & $1.6^{*}$ & ERF78509.1 \\
\hline Gab_1654 & Outer membrane phospholipase A & Insoluble & $1.3^{*}$ & ERF79322.1 \\
\hline Gab_2224 & Outer membrane receptor proteins, mostly Fe transport & Insoluble & 1.3 & ERF78217.1 \\
\hline Gab_2192 & Outer membrane protein $\mathrm{W}$ & Insoluble & 1.2 & ERF78317.1 \\
\hline Gab_1450 & Opacity protein and related surface antigens & Insoluble & 1.2 & ERF79004.1 \\
\hline Gab_0652 & Organic solvent tolerance protein OstA & Insoluble & 1.2 & ERF78644.1 \\
\hline Gab_1283 & Long-chain fatty acid transport protein & Insoluble & 1.2 & ERF77302.1 \\
\hline Gab_0047 & Metal-dependent proteases with possible chaperone activity & Soluble & 1.0 & ERF77629.1 \\
\hline Gab_1162 & P pilus assembly protein, porin PapC & Insoluble & 1.0 & ERF79423.1 \\
\hline Gab_1192 & Surface lipoprotein & Insoluble & 1.0 & ERF78832.1 \\
\hline Gab_1397 & Outer membrane protein & Insoluble & 1.0 & ERF79124.1 \\
\hline Gab_0925 & Hypothetical protein & Insoluble & 1.0 & ERF77284.1 \\
\hline Gab_0186 & Membrane-bound lytic murein transglycosylase & Insoluble & 1.0 & ERF78366.1 \\
\hline Gab_2304 & Glycerophosphoryl diester phosphodiesterase & Soluble & 0.9 & ERF77421.1 \\
\hline OmpC & Outer membrane protein (porin) & Insoluble & 0.9 & KF160335 \\
\hline Gab_0572 ${ }^{d}$ & F17-like fimbrial subunit & Insoluble & 0.9 & ERF79277.1 \\
\hline Gab_1245 & Hemolysin activation/secretion protein & Insoluble & 0.9 & ERF78979.1 \\
\hline
\end{tabular}

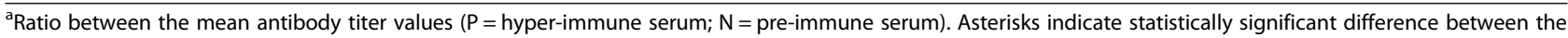
two groups $(*=P<0.05$, *** $P<0.001)$.

${ }^{\mathrm{b}}$ Proteins ranked within the Top20 of the $G$. anatis $12656-12$ proteome by VacFinder ${ }^{\circledast}$.

'Previously described in [35]. Due to the size of the protein it was cloned, expressed and purified as two halves.

dPreviously described in [24].

ePreviously described in [36]. 
for each protein (Table 3). A significant and specific reaction with hyper-immune antiserum was identified for 12 of the 27 recombinant proteins tested (Figure 1), namely GtxA (both halves of the protein), FlfA, Gab_0091, Gab_0523, Gab_1309, Gab_1575, Gab_1654, Gab_1755, Gab_2156, Gab_2312 and Gab_2348. These results indicate (i) that these 12 proteins are expressed in vivo by $G$. anatis $12656-12$, (ii) that the proteins are recognized by the chicken immune system, and (iii) that the proteins elicit a specific antibody response. The remaining proteins were not significantly recognized by the hyper-immune antiserum.

\section{Screening of protective potential by VacFinder ${ }^{\circledR}$}

To provide an additional prediction of the protective potential of the 27 proteins available in recombinant form, the protein sequences were analyzed in silico with the VacFinder ${ }^{\bullet}$ algorithm. The entire G. anatis strain 1265612 proteome (approximately 2500 proteins) was analyzed and ranked for protective potential. Proteins ranked in the Top20 are those predicted to have the highest protective potential (Table 3). Of the 27 proteins cloned and expressed in E. coli, only Gab_1309 and Gab_2312 were ranked within the Top20 VacFinder ${ }^{\bullet}$ hits.

\section{Conservation of Gab_1309 and Gab_2312}

Two of the 27 proteins, Gab_1309 and Gab_2312, elicited a significant ELISA response and were ranked in the Top20 proteins with protective potential in the G. anatis 12656-12 proteome as determined by VacFinder ${ }^{\oplus}$, suggesting that these proteins should be prioritized in further analyses. Both proteins were expressed in E. coli with an $\mathrm{N}$-terminus $\mathrm{His}_{6}$-tag and purified in soluble form. Due to the high degree of predicted hydrophobicity within the Cterminal region of Gab_2312, as well as the size of the whole protein $(325.7 \mathrm{kDa})$, only a small part (338 residues) was included in the final recombinant protein. Homologs of Gab_1309 and Gab_2312 were identified within the genomes of all the 10 strains included in this study, as well as in the recently sequenced G. anatis strain UMN179 (UMN_1211 and UMN_1565) [27], further supporting their potential as broadly protective immunogens. To determine the level of protein sequence conservation of Gab_1309 and Gab_2312, multiple alignments were conducted against the protein homologs from other G. anatis strains. The Gab_1309 protein sequences were almost identical across all strains (Additional file 4). On the other hand, the Gab_2312 protein sequences varied considerably in length from 2157 residues in G. anatis strain F149 to 5202 residues in G. genomospecies 2 strain CCM5976. Despite this difference, several well-conserved sections could be identified within the sequences, indicating a degree of conservation within the structure and the presence of common epitopes. Additional file 5 shows the alignment between the 338 residues included in the recombinant protein and the corresponding parts in the protein homologs.

\section{Potential protective capacity}

To evaluate the protective potential in vivo of the five most promising vaccine candidates (GtxA-N, FlfA, Gab_1309, Gab_2156, or Gab_2312), groups of four chickens were each immunized with one of the recombinant proteins, followed by intraperitoneal challenge with G. anatis 12656-12. G. anatis was recovered in pure culture from chickens within all the immunized groups, as well as

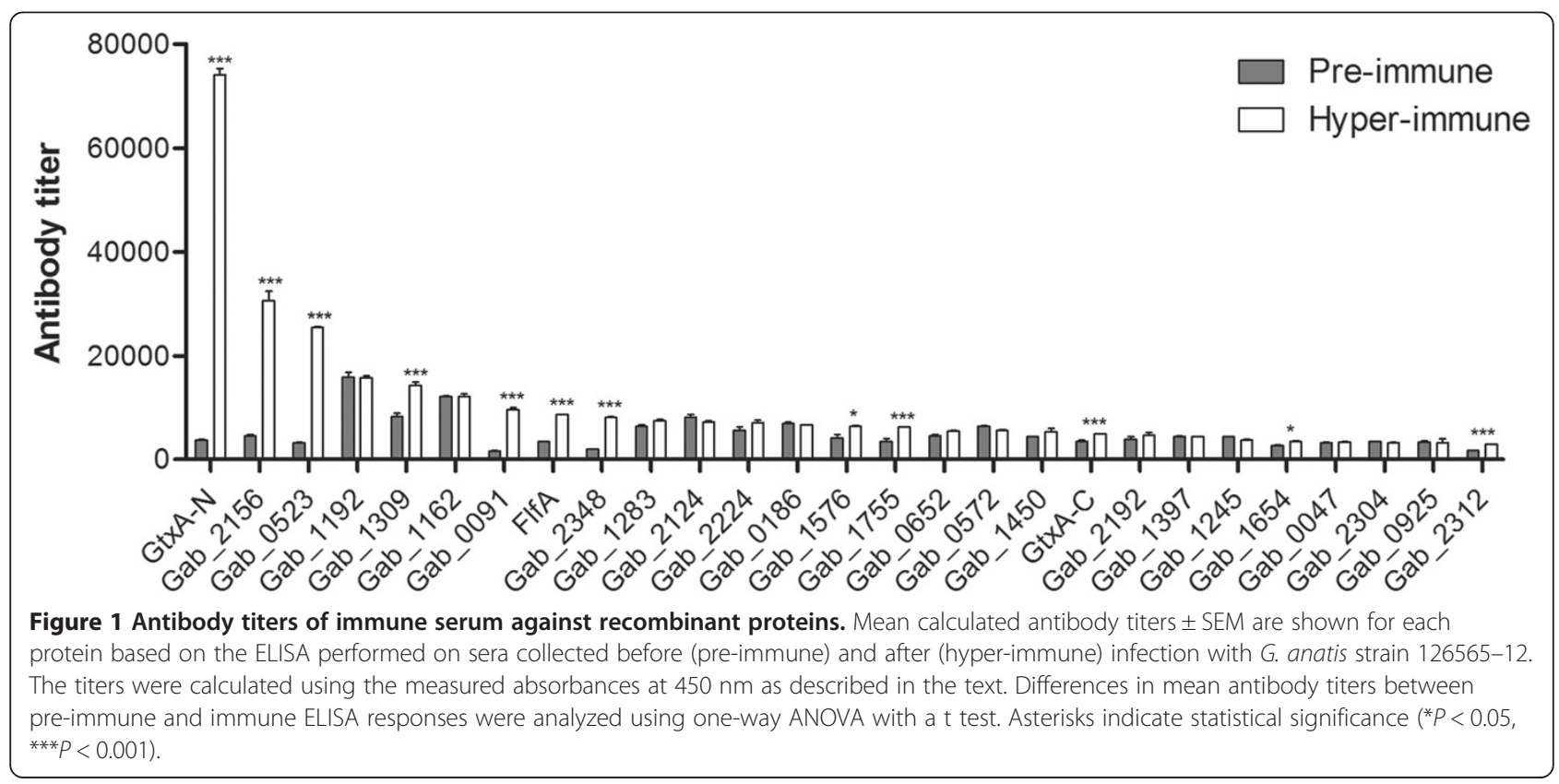


from the non-immunized group. However, two chickens from the group immunized with GtxA-N and one chicken from the group immunized with FlfA were culturenegative. A significant lower lesion score was found in the group immunized with GtxA-N $(P=0.02)$, FlfA $(P=0.04)$ and Gab_1309 $(P=0.02)$ when compared to the nonimmunized group (Figure 2), indicating a protective potential of these three proteins. The two groups immunized with Gab_2156 or Gab_2312 did not show a significant difference when compared with the nonimmunized group.

\section{Discussion}

Novel prevention and treatment strategies are urgently needed to prevent $G$. anatis infections in the reproductive tract of chickens. In this study, a pan-genomic RV approach $[15,23]$ was applied to identify novel and potentially broadly protective immunogens from G. anatis. The screening procedures and the main results are summarized in Figure 3. Of the 42 in silico predicted immunogens (Table 2), 27 proteins were successfully expressed in E. coli (Table 1), and of these, two novel proteins, Gab_1309 and Gab_2312, elicited a significant ELISA response and were also ranked in the Top20 of the $G$. anatis $12656-12$ proteome by VacFinder ${ }^{\oplus}$. Furthermore, these two proteins were present in all 10 strains

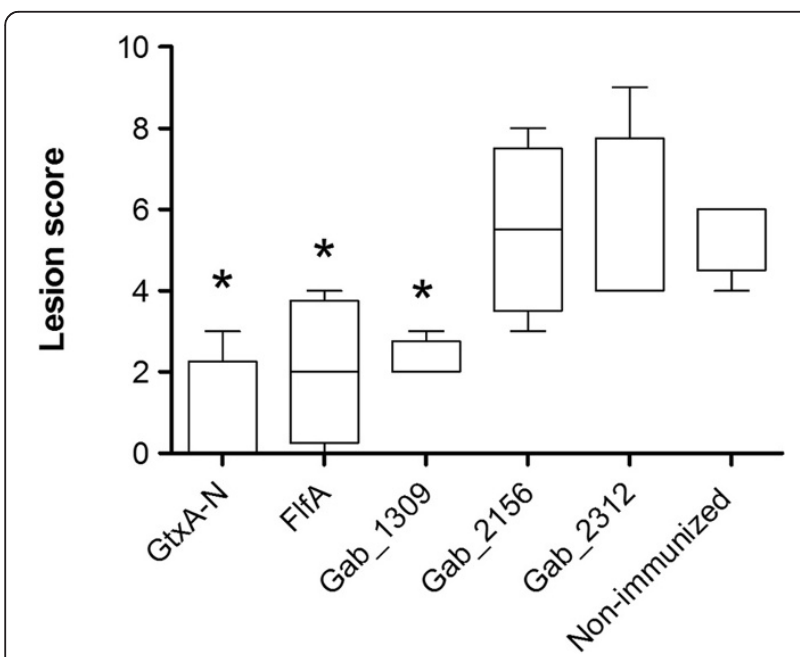

Figure 2 Immunization of chickens with recombinant proteins. Chickens were immunized once with $100 \mu \mathrm{g}$ recombinant protein (GtxA-N, FlfA, Gab_1309, Gab_2156, or Gab_2312) or a placebo (non-immunized), followed by intraperitoneal challenge with $G$. anatis 12656-12. The scoring of the lesions found in the peritoneum was done according to three parameters: (i) inflammatory reaction, (ii) amount of exudate, and (iii) clarity of the peritoneal surfaces. All parameters were scored on a scale from $0-3$, thus giving a maximum score of 9 . The horizontal lines shows the group median, and the difference between the lesions scores of immunized and non-immunized groups was analyzed using Mann Whitney $U$ test. Asterisks indicate statistical significance $\left({ }^{*} P<0.05\right)$. included in this study as well as in the recently sequenced genome from G. anatis strain UMN179 [27].

Gab_1309 is a predicted lipoprotein, and this annotation is supported by the DOLOP database [50]. The protein sequence of Gab_1309 shows sequence similarity to the NlpD lipoprotein from Yersinia pestis [51]. By use of the Conserved Domain Database (CDD) feature in BLASTp [52], an N-terminal LysM domain and a Cterminal M23 peptidase domain can be identified in Gab_1309. The LysM domain is widespread among several bacterial species and is involved in peptidoglycanbinding and bacterial cell wall degradation [53,54], while the M23 family of endopeptidases is thought to be involved in bacterial cell wall separation [55]. Further studies are warranted to determine the specific function and role of Gab_1309 in G. anatis pathogenesis.

The C-terminal section of the second promising novel vaccine candidate identified in this study, Gab_2312, demonstrated $34 \%$ sequence similarity (conserved or identical residues) to the $200 \mathrm{kDa}$ extracellular matrix protein adhesin A (EmaA) from Aggregatibacter actinomycetemcomitans. EmaA is widespread among A. actinomycetemcomitans strains [56] and belongs to the family of trimeric autotransporter adhesins (TAAs) [57]. TAAs are a group of homotrimeric virulence-related proteins in Gram-negative bacteria that primarily act as adhesins [58]. Interestingly, the Neisseria adhesin A (NadA) protein from MenB, which is one of the proteins in the recently approved $4 \mathrm{CMenB}$ vaccine $\left(\right.$ Bexsero $^{\circ}$ ), also belongs to this family of TAAs [59], further suggesting a protective potential of Gab_2312. The prediction of Gab_2312 as a TAA protein was further confirmed using the recently developed domain annotation workflow of TAAs (daTAAs) [60].

Although Gab_1309 and Gab_2312 were the only proteins identified by both the ELISA screening and the in silico VacFinder ${ }^{\odot}$ analysis, a number of proteins elicited a significant response as measured by ELISA, indicating that these proteins are expressed and immunogenic during $G$. anatis infection. It is currently unclear whether proteins that do not stimulate a natural immune response should be included as vaccine candidates. As our intraperitoneal immunization procedure bypassed the mucosal surface of e.g. the salpinx, this may not have induced a broad based natural immunological response, which in turn could explain why some proteins failed to induce a significant antibody response. However, studies have shown that high antigenicity of a protein does not necessarily lead to protection [61], questioning the validity of the antigen-specific titer as a marker of the overall ability to stimulate a protective immune response in vivo [62]. On the other hand, serological titers have been demonstrated to provide useful information about the reactivity of certain antigens to antibodies and thereby 


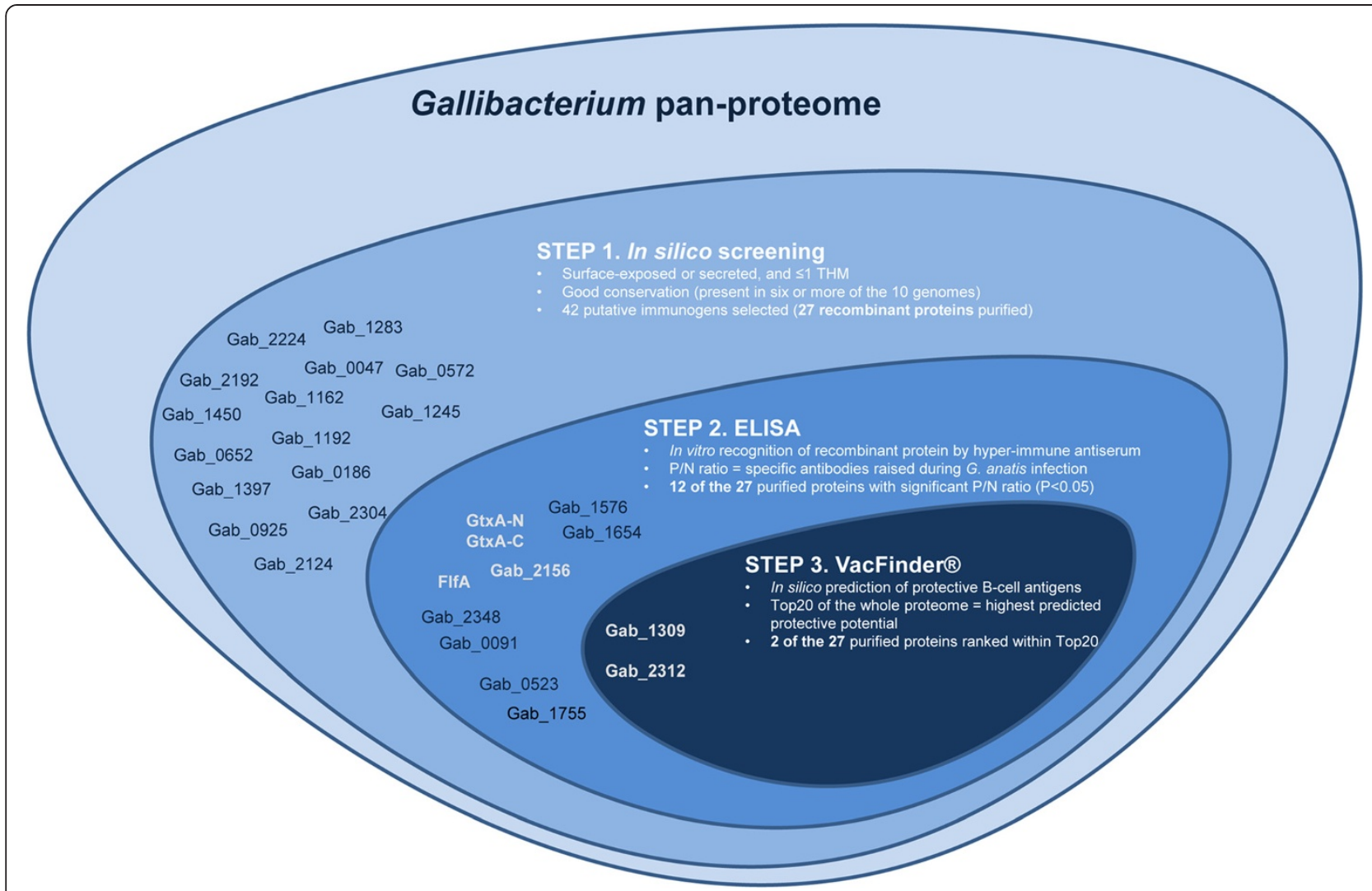

Figure 3 Identification and selection of immunogens from Gallibacterium. Summary of the three screening procedures used to identify and select putative immunogens from the Gallibacterium proteome. The 27 proteins successfully cloned, expressed and purified are listed and placed based on the screening results. Future investigations should focus on the proteins marked in white.

give indications about their potential as vaccine candidates [62]. In support of the ELISA antigen screening approach, three of the 10 proteins identified by the ELISA screening; GtxA, FlfA and Gab_2156, have recently been demonstrated as important, well-conserved G. anatis virulencefactors. GtxA is a large, cytolytic RTX toxin responsible for both the haemolytic and leukotoxic activity of G. anatis [26,35], while FlfA and Gab_2156 are both subunits of F17-like fimbriae [24]. To this, FlfA has been suggested to play a role in the tissue tropism of $G$. anatis by promoting adhesion to the epithelial lining in the reproductive tract and beyond during the typical course of disease [24]. The identification of GtxA, FlfA and Gab_2156 by ELISA further supports the predictive potential and importance of this screening approach, where particularly the $\mathrm{N}$ terminal part of the GtxA-N elicited an extremely high antibody response in comparison to the remaining 26 proteins investigated (Figure 1 and Table 3), thereby suggesting that this part of the protein is particularly promising as a vaccine candidate. This suggestion is supported by a previous study by [63], demonstrating the protective potential of the $\mathrm{N}$-terminal portion of the RTX protein, ApxI, against infections caused by Actinobacillus pleuropneumoniae.
The use of hyper-immune antiserum to screen for antigenic potential has previously been used successfully to identify putative immunogens from Bacillus anthracis, and in that study, the control sera (pre-immune antiserum) consisted of a mixture of naïve animal sera [64]. In our study, the pre-immune antiserum and hyperimmune serum was obtained from the same chickens before and after G. anatis 12656-12 infection. However, the chickens were found to be positive for G. anatis in the trachea and cloaca prior to infection. Since G. anatis is a typical part of the microflora in these organ systems [6], we find that this reflects the natural in vivo condition, which allows us to identify those proteins significantly expressed and exposed to the chicken immune system during infection. Thus, the ELISA screening applied in this study can be considered a semi-in vivo-evaluation and an important screening assay to evaluate antigenic potentials of recombinant proteins.

Of the 27 proteins tested by ELISA, 15 were not recognized by hyper-immune antiserum. However, these proteins might still possess immunogenic potential, as it is well-established that in vitro assessments may miss some proteins [14]. Moreover, a recent study focused interest on non-immunodominant protein regions for vaccine 
development and suggested the importance of analyzing major surface-exposed proteins for the presence of subregions that elicit protective immunity as a complement to the RV approach [65]. Additionally, the insolubility of many of the proteins tested by ELISA might also lead to false-negative titer-values, as it has been shown that linear epitopes are less likely to be immunodominant and elicit a good B-cell response if the protein possesses a higher-order structure [66]. On the other hand, the folding of a recombinant protein is not necessarily equivalent to the native structure of the protein, and moreover, folded recombinant proteins might expose epitopes normally hidden [14], and thereby lead to a false-positive ELISA response.

To provide an additional prediction of the protective potential, the sequences of 27 proteins were ranked within the $G$. anatis $12656-12$ proteome by use of the in silico VacFinder ${ }^{\circ}$ platform, in order to add an extra selective criterion. The ranking by VacFinder ${ }^{\circledR}$ is based on the predicted ability of a protein to elicit a high protective antibody response. Thus, the identified proteins are not affected by possible solubility problems or competing immunodominant epitopes. Moreover, VacFinder ${ }^{\circ}$ does not consider general practicalities of cloning, expression and purification. The combination of VacFinder $^{\circledR}$ prediction and ELISA screening identified two proteins, namely the above-mentioned Gab_1309 and Gab_2312. However, the previously identified and wellconserved virulence factors, GtxA, FlfA and Gab_2156, were not predicted as highly protective by VacFinder ${ }^{\odot}$. Leaving out GtxA, which is an exotoxin and not possible for VacFinder ${ }^{\ominus}$ to predict, FlfA and Gab_2156 were respectively ranked \#58 and \#41 out of the whole proteome. Hence, the Top20 of the proteome by VacFinder ${ }^{\circledast}$ is predicted to elicit the highest protective antibody response, yet this study demonstrates that proteins with a lower predicted protectiveness can be highly immunogenic.

Finally, the protective potential of the five most promising vaccine candidates; GtxA-N, FlfA, Gab_1309, Gab_2156 and Gab_2312, was evaluated in vivo. The results from these preliminary in vivo immunization trials indicated that at least GtxA-N, FlfA and Gab_1309 are promising vaccine candidates with a good protective potential. These results correspond well with previous results demonstrating the in vivo protective potential of FlfA [24]. Further studies, including larger group sizes, different doses and repeated immunization, are needed to confirm the protective potential of the recombinant proteins. Moreover, the ability of the recombinant proteins to elicit a broadly cross-protective immune response against heterologous strains should also be investigated. Still, the results presented in this paper provide an important step towards the development of a new and broadly protective $G$. anatis vaccine.

\section{Additional files}

Additional file 1: $E$. coli strains and plasmids. E. coli strains and plasmid used in this study to clone and express recombinant proteins [67].

Additional file 2: Cloning and protein expression. Detailed description of the methods used for the cloning as well as the small scale and large-scale protein expression and purification [37,38,68-70].

Additional file 3: Primer sequences, PCR products and expression vectors. A table summarizing the primer sequences used for gene amplification, the size of the resulting PCR product and the final expression vector chosen for protein expression from each of the $G$. anatis 12656-12 genes that were successfully small-scaled cloned and expressed [24,35,36].

Additional file 4: Multiple sequence alignment of Gab_1309. A multiple alignment between Gab_1309 and homologs was conducted using MAFFT (v7.130b) [45] and formatted using Jalview 2.8.0b1 [46]. Amino acids were colored in blue based on their conservation (dark blue = fully conserved).

Additional file 5: Multiple sequence alignment of recombinant Gab_2312. A multiple alignment between the 338-residue recombinant Gab_2312 protein sequence and Gab_2312 protein homologs was conducted using MAFFT (v7.130b) [45] and formatted using Jalview 2.8.0b1 [46]. Amino acids were colored in blue based on their conservation (dark blue $=$ fully conserved). The two head domains included in the recombinant protein, which were predicted by the domain annotation workflow of TAAs (daTAAs) [60], are marked with red and green boxes, respectively.

\section{Abbreviations}

RV: Reverse vaccinology; TMH: Trans-membrane helix; G. anatis 12656-12: Gallibacterium anatis biovar haemolytica strain 12656-12; MenB: Neisseria meningitides seropgroup B; LIC: Ligation-independent cloning; ELISA: Enzyme-linked immunosorbent assay; TAA: Trimeric autotransporter adhesin.

\section{Competing interests}

The authors declare that they have no competing interests.

\section{Authors' contributions}

RJB contributed to the design of the study, carried out the experiments and drafted the manuscript. EK and TS carried out the genome assembly, annotation and submission to Genbank. IP prepared the pan-proteome and carried out the in silico selection of the putative immunogens. JB and BA participated in the small-scale cloning and expression of the recombinant proteins. TKN participated in the large-scale expression and purification of the recombinant proteins. SEP carried out the in vivo experiments. AHM carried out the VacFinder predictions. AMB conceived the study, participated in its design and its coordination, and helped to draft the manuscript.

All authors read and approved the final manuscript.

\section{Acknowledgements}

This work was supported by the Danish Research Council for Technology and Production, grant 09-065909, and a PhD stipend from the Faculty of Life Sciences, Copenhagen University. The authors acknowledge the excellent technical assistance of Kate Rainczuk, for her help with the Gateway cloning, and Sara Bjørn, for her help with the LIC cloning.

\section{Author details}

${ }^{1}$ Department of Veterinary Disease Biology, Faculty of Health and Medical Sciences, University of Copenhagen, 1870 Frederiksberg C, Denmark. ${ }^{2}$ Victorian Bioinformatics Consortium, Monash University, 3800 Clayton, Melbourne, Australia. ${ }^{3}$ The Novo Nordisk Foundation Center for Protein Research, Faculty of Health and Medical Sciences, University of Copenhagen, 2200 Copenhagen N, Denmark. ${ }^{4}$ Center for Biological Sequence Analysis, Technical University of Denmark, 2800 Lyngby, Denmark. ${ }^{5}$ Evaxion Biotech North America LLC, Wilmington, USA. ${ }^{6}$ Department of Microbiology, Monash University, 3800 Clayton, Melbourne, Australia. ${ }^{7}$ Australian Research Council Centre of Excellence in Structural and Functional Microbial Genomics, Department of Microbiology, Monash University, 3800 Clayton, Melbourne, Australia. 
Received: 6 May 2014 Accepted: 21 July 2014

Published: 8 August 2014

\section{References}

1. AVEC: Annual report 2011. Assoc Poult Processors Poult Trade EU Ctries 2011, 41:1-52.

2. Marangon S, Busani L: The use of vaccination in poultry production. Rev Sci Tech 2007, 26:265-274.

3. Christensen H, Bisgaard M, Bojesen AM, Mutters R, Olsen JE: Genetic relationships among avian isolates classified as Pasteurella haemolytica, "Actinobacillus salpingitidis" or Pasteurella anatis with proposal of Gallibacterium anatis gen. nov., comb. nov. and description of additional genomospecies within Gallibacterium gen. nov. Int I Syst Evol Microbiol 2003, 53:275-287.

4. Bisgaard M, Korczak BM, Busse $\mathrm{H}-\mathrm{J}$, Kuhnert $\mathrm{P}$, Bojesen AM, Christensen $\mathrm{H}$ : Classification of the taxon 2 and taxon 3 complex of Bisgaard within Gallibacterium and description of Gallibacterium melopsittaci sp. nov., Gallibacterium trehalosifermentans sp. nov. and Gallibacterium salpingitidis sp. nov. Int I Syst Evol Microbiol 2009, 59:735-744.

5. Bisgaard M: Incidence of Pasteurella haemolytica in the respiratory tract of apparently healthy chickens and chickens with infectious bronchitis: characterisation of 213 strains. Avian Pathol 1977, 6:285-292

6. Bojesen AM, Nielsen SS, Bisgaard M: Prevalence and transmission of haemolytic Gallibacterium species in chicken production systems with different biosecurity levels. Avian Pathol 2003, 5:503-510.

7. Mirle $\mathrm{C}$, Schöngarth $\mathrm{M}$, Meinhart $\mathrm{H}, \mathrm{Olm} \mathrm{U}$ : Untersuchungen zu auftreten and bedeutung von Pasteurella haemolytica infektionen bei hennen unter besonderer berücksichtigung von erkrankungen des legeapparates. Mh Vet Med 1991, 46:545-549 (in German).

8. Jordan FTW, Williams NJ, Wattret A, Jones T: Observations on salpingitis, peritonitis and salpingoperitonitis in a layer breeder flock. Vet Rec 2005, 157:573-577.

9. Neubauer C, De Souza-Pilz M, Bojesen AM, Bisgaard M, Hess M: Tissue distribution of haemolytic Gallibacterium anatis isolates in laying birds with reproductive disorders. Avian Pathol 2009, 38:1-7.

10. Bojesen AM, Christensen JP, Bisgaard M: Gallibacterium infections and other avian Pasteurellaceae. In Poultry diseases. $6^{\text {th }}$ edition. Edited by Pattison M, Mcmullin PF, Bradbury JM, Alexander DJ. Edinburg: Saunders Elsevier; 2008:160-163.

11. Bojesen $A M$, Vazquez ME, Bager RJ, Ifrah D, Gonzalez C, Aarestrup FM: Antimicrobial susceptibility and tetracycline resistance determinant genotyping of Gallibacterium anatis. Vet Microbiol 2011, 148:105-110

12. Schumacher T, Vazquez ME, Leon-Kempis MR: Analysis of strains of Gallibacterium anatis by agar gel precipitation and determination of cross reactivity [Poster]. Sorrento, Italy: International Pasteurellaceae Society Meeting; 2008

13. Fleischmann RD, Adams MD, White O, Clayton RA, Kirkness EF, Kerlavage AR, Bult CJ, Tomb JF, Dougherty BA, Merrick JM: Whole-genome random sequencing and assembly of Haemophilus influenzae Rd. Science 1995, 269:496-512.

14. Rinaudo CD, Telford JL, Rappuoli R, Seib KL: Vaccinology in the genome era. J Clin Invest 2009, 119:2515-2525.

15. Rappuoli R: Reverse vaccinology, a genome-based approach to vaccine development. Vaccine 2001, 19:2688-2691.

16. Pizza M, Scarlato V, Masignani V, Giuliani MM, Aricò B, Comanducci M, Jennings GT, Baldi L, Bartolini E, Capecchi B, Galeotti CL, Luzzi E, Manetti R, Marchetti E, Mora M, Nuti S, Ratti G, Santini L, Savino S, Scarselli M, Storni E, Zuo P, Broeker M, Hundt E, Knapp B, Blair E, Mason T, Tettelin H, Hood DW, Jeffries $A C$, et al: Identification of vaccine candidates against serogroup B meningococcus by whole-genome sequencing. Science 2000, 287:1816-1820.

17. Tettelin H, Saunders NJ, Heidelberg J, Jeffries AC, Nelson KE, Eisen JA, Ketchum KA, Hood DW, Peden JF, Dodson RJ, Nelson WC, Gwinn ML, DeBoy R, Peterson JD, Hickey EK, Haft DH, Salzberg SL, White O, Fleischmann RD, Dougherty BA, Mason T, Ciecko A, Parksey DS, Blair E, Cittone $\mathrm{H}$, Clark EB, Cotton MD, Utterback TR, Khouri H, Qin H, et al: Complete genome sequence of Neisseria meningitidis serogroup B strain MC58. Science 2000, 287:1809-1815.

18. Giuliani MM, Adu-Bobie J, Comanducci M, Aricò B, Savino S, Santini L, Brunelli B, Bambini S, Biolchi A, Capecchi B, Cartocci E, Ciucchi L, Di Marcello F, Ferlicca F, Galli B, Luzzi E, Masignani V, Serruto D, Veggi D, Contorni M,
Morandi M, Bartalesi A, Cinotti V, Mannucci D, Titta F, Ovidi E, Welsch JA, Granoff D, Rappuoli R, Pizza M: A universal vaccine for serogroup B meningococcus. Proc Natl Acad Sci U S A 2006, 103:10834-10839.

19. Carter N: Multicomponent meningococcal serogroup $B$ vaccine $\left(4 \mathrm{CMenB}\right.$; Bexsero $\left.{ }^{\circ}\right)$ : a review of its use in primary and booster vaccination. BioDrugs 2013, 3:263-274.

20. Donati C, Rappuoli R: Reverse vaccinology in the 21st century: improvements over the original design. Ann N Y Acad Sci 2013, 1285:115-132

21. Tettelin H, Masignani V, Cieslewicz MJ, Donati C, Medini D, Ward NL, Angiuoli SV, Crabtree J, Jones AL, Durkin AS, Deboy RT, Davidsen TM, Mora M, Scarselli M, Margarit y Ros I, Peterson JD, Hauser CR, Sundaram JP, Nelson WC, Madupu R, Brinkac LM, Dodson RJ, Rosovitz MJ, Sullivan SA, Daugherty SC, Haft DH, Selengut J, Gwinn ML, Zhou L, Zafar N, et al: Genome analysis of multiple pathogenic isolates of Streptococcus agalactiae: implications for the microbial "pan-genome". Proc Natl Acad Sci U S A 2005, 102:13950-13955.

22. Maione D, Margarit I, Rinaudo CD, Masignani V, Mora M, Scarselli M, Tettelin H, Brettoni C, lacobini ET, Rosini R, D'Agostino N, Miorin L, Buccato S, Mariani M, Galli G, Nogarotto R, Nardi-Dei V, Vegni F, Fraser C, Mancuso G, Teti G, Madoff LC, Paoletti LC, Rappuoli R, Kasper DL, Telford JL, Grandi G: Identification of a universal Group B streptococcus vaccine by multiple genome screen. Science 2005, 309:148-150.

23. Medini D, Donati C, Tettelin H, Masignani V, Rappuoli R: The microbial pan-genome. Curr Opin Genet Dev 2005, 15:589-594.

24. Bager RJ, Nesta B, Pors SE, Soriani M, Serino L, Boyce JD, Adler B, Bojesen AM: The fimbrial protein FIfA from Gallibacterium anatis is a virulence factor and vaccine candidate. Infect Immun 2013, 81:1964-1973.

25. Bojesen AM, Torpdahl M, Christensen H, Olsen JE, Bisgaard M: Genetic diversity of Gallibacterium anatis isolates from different chicken flocks. J Clin Microbiol 2003, 41:2737-2740.

26. Kristensen BM, Frees D, Bojesen AM: Expression and secretion of the RTX-toxin GtxA among members of the genus Gallibacterium. Vet Microbiol 2011, 153:116-123.

27. Johnson TJ, Danzeisen JL, Trampel D, Nolan LK, Seemann T, Bager RJ, Bojesen AM: Genome analysis and phylogenetic relatedness of Gallibacterium anatis strains from poultry. PLoS One 2013, 1:e54844.

28. The VelvetOptimiser 2.0 de novo sequence assembler. [http://www. vicbioinformatics.com/software.velvetoptimiser.shtml]

29. Seemann T: Prokka: rapid prokaryotic genome annotation. Bioinformatics 2014, 30:2068-2069.

30. Yu NY, Wagner JR, Laird MR, Melli G, Rey S, Lo R, Dao P, Sahinalp SC, Ester M, Foster LJ, Brinkman FS: PSORTb 3.0: improved protein subcellular localization prediction with refined localization subcategories and predictive capabilities for all prokaryotes. Bioinformatics 2010, 13:1608-1615.

31. Bendtsen JD, Nielsen $H$, von Heijne $G$, Brunak S: Improved prediction of signal peptides: SignalP 3.0. J Mol Biol 2004, 4:783-795.

32. Krogh A, Larsson B, von Heijne G, Sonnhammer EL: Predicting transmembrane protein topology with a hidden Markov model: application to complete genomes. J Mol Biol 2001, 3:567-580.

33. Altschul SF, Gish W, Miller W, Myers EW, Lipman DJ: Basic local alignment search tool. J Mol Biol 1990, 215:403-410.

34. Rice P, Longden I, Bleasby A: EMBOSS: the European molecular biology open software suite. Trends Genet 2000, 16:276-277.

35. Kristensen BM, Frees D, Bojesen AM: GtxA from Gallibacterium anatis, a cytolytic RTX-toxin with a novel domain organisation. Vet Res 2010, 41:25.

36. Bager RJ, Persson G, Nesta B, Soriani M, Serino L, Jeppsson M, Nielsen TK, Bojesen AM: Outer membrane vesicles reflect environmental cues in Gallibacterium anatis. Vet Microbiol 2013, 167:565-572.

37. Al-Hasani K, Boyce J, McCarl VP, Bottomley S, Wilkie I, Adler B: Identification of novel immunogens in Pasteurella multocida. Microb Cell Fact 2007, 6:3.

38. Gräslund S, Sagemark J, Berglund H, Dahlgren L-G, Flores A, Hammarström M, Johansson I, Kotenyova T, Nilsson M, Nordlund P, Weigelt J: The use of systematic $\mathrm{N}$ - and C-terminal deletions to promote production and structural studies of recombinant proteins. Protein Expr Purif 2008, 2:210-221

39. Bojesen AM, Nielsen OL, Christensen JP, Bisgaard M: In vivo studies of Gallibacterium anatis infection in chickens. Avian Pathol 2004, 33:145-152.

40. Raida MK, Nylén J, Holten-Andersen L, Buchmann K: Association between plasma antibody response and protection in rainbow trout 
Oncorhynchus mykiss immersion vaccinated against Yersinia ruckeri. PLoS One 2011, 6:e18832.

41. Villumsen KR, Dalsgaard I, Holten-Andersen L, Raida MK: Potential role of specific antibodies as important vaccine induced protective mechanism against Aeromonas salmonicida in rainbow trout. PLoS One 2012, 7:e46733.

42. The MyAssays ${ }^{\oplus}$ Antibody Titer Calculation Software. [http://www. myassays.com/antibody-titers.assay]

43. Case JT, Ardans AA, Bolton DC, Reynolds BJ: Optimization of parameters for detecting antibodies against infectious bronchitis virus using an enzyme-linked immunosorbent assay: temporal response to vaccination and challenge with live virus. Avian Dis 1983, 27:196-210.

44. Doytchinova IA, Flower DR: VaxiJen: a server for prediction of protective antigens, tumor antigens and subunit vaccines. BMC Bioinformatics 2007 8:4.

45. Katoh K, Standley DM: MAFFT multiple sequence alignment software version 7: improvements in performance and usability. Mol Biol Evol 2013, 30:772-780.

46. Waterhouse AM, Procter JB, Martin DMA, Clamp M, Barton GJ: Jalview Version 2 - a multiple sequence alignment editor and analysis workbench. Bioinformatics 2009, 25:1189-1191.

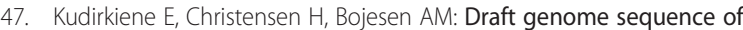
Gallibacterium anatis biovar haemolytica 12656-12 Liver, an isolate obtained from the liver of a septicaemic chicken. Genome Announc 2013, 1:e00810-13.

48. The NCBI Sequence Read Archive (SRA). [https://www.ncbi.nlm.nih.gov/sra]

49. Korepanova A, Gao FP, Hua Y, Qin H, Nakamoto RK, Cross TA: Cloning and expression of multiple integral membrane proteins from Mycobacterium tuberculosis in Escherichia coli. Protein Sci 2005, 14:148-158.

50. Babu MM, Sankaran K: DOLOP-database of bacterial lipoproteins. Bioinformatics 2002, 18:641-643.

51. Tidhar A, Flashner $Y$, Cohen S, Levi Y, Zauberman A, Gur D, Aftalion M, Elhanany E, Zvi A, Shafferman A, Mamroud E: The NIpD lipoprotein is a novel Yersinia pestis virulence factor essential for the development of plague. PLoS One 2009, 4:e7023.

52. Marchler-Bauer A, Lu S, Anderson JB, Chitsaz F, Derbyshire MK, DeWeese-Scott C, Fong JH, Geer LY, Geer RC, Gonzales NR, Gwadz M, Hurwitz DI, Jackson JD, Ke Z, Lanczycki CJ, Lu F, Marchler GH, Mullokandov M, Omelchenko MV, Robertson CL, Song JS, Thanki N, Yamashita RA, Zhang D, Zhang N, Zheng C, Bryant SH: CDD: a Conserved Domain Database for the functional annotation of proteins. Nucleic Acids Res 2011, 39:D225-D229.

53. Bateman A, Bycroft M: The structure of a LysM domain from E. coli membrane-bound lytic murein transglycosylase D (MltD). J Mol Biol 2000, 299:1113-1139.

54. Buist G, Steen A, Kok J, Kuipers OP: LysM, a widely distributed protein motif for binding to (peptido)glycans. Mol Microbiol 2008, 68:838-847.

55. Bernhardt TG, de Boer PA: Screening for synthetic lethal mutants in Escherichia coli and identification of EnvC (YibP) as a periplasmic septal ring factor with murein hydrolase activity. Mol Microbiol 2004 52:1255-1269.

56. Mintz KP: Identification of an extracellular matrix protein adhesin, EmaA which mediates the adhesion of Actinobacillus actinomycetemcomitans to collagen. Microbiology 2004, 150:2677-2688.

57. Linke D, Riess T, Autenrieth IB, Lupas A, Kempf VAJ: Trimeric autotransporter adhesins: variable structure, common function. Trends Microbiol 2006, 14:264-270.

58. Łyskowski A, Leo JC, Goldman A: Structure and biology of trimeric autotransporter adhesins. Adv Exp Med Biol 2011, 715:143-158.

59. Serruto D, Bottomley MJ, Ram S, Giuliani MM, Rappuoli R: The new multicomponent vaccine against meningococcal serogroup $B, 4 C M e n B$ : immunological, functional and structural characterization of the antigens. Vaccines 2012, 30(Suppl 2):B87-B97.

60. Szczesny $P$, Lupas A: Domain annotation of trimeric autotransporter adhesins-daTAA. Bioinformatics 2008, 24:1251-1256.

61. Ooka H, Terkawi MA, Goo Y-K, Luo Y, Li Y: Babesia microti: molecular and antigenic characterizations of a novel 94-kDa protein (BmP94). Exp Parasitol 2011, 127:287-293.

62. Chao C-C, Huber ES, Porter TB, Zhang Z, Ching W-M: Analysis of the cross-reactivity of various $56 \mathrm{kDa}$ recombinant protein antigens with serum samples collected after Orientia tsutsugamushi infection by ELISA. Am J Trop Med Hyg 2011, 84:967-972.
63. Seah JN, Frey J, Kwang J: The N-terminal domain of RTX toxin Apxl of Actinobacillus pleuropneumoniae elicits protective immunity in mice. Infect Immun 2002, 70:6464-6467.

64. Ariel N, Zvi A, Grosfeld H, Gat O, Inbar Y, Velan B, Cohen S, Shafferman A Search for potential vaccine candidate open reading frames in the Bacillus anthracis virulence plasmid pXO1: in silico and in vitro screening. Infect Immun 2002, 70:6817-6827.

65. Stålhammar-Carlemalm M, Waldemarsson J, Johnsson E, Areschoug T, Lindahl G: Nonimmunodominant regions are effective as building blocks in a streptococcal fusion protein vaccine. Cell Host Microbe 2007, 2:427-434.

66. Ito $H$, Nakashima T, So T, Hirata M, Inoue M: Immunodominance of conformation-dependent B-cell epitopes of protein antigens. Biochem Biophys Res Commun 2003, 308:770-776.

67. Keyburn AL, Boyce JD, Vaz P, Bannam TL, Ford ME, Parker D, Di Rubbo A, Rood Jl, Moore RJ: NetB, a new toxin that is associated with avian necrotic enteritis caused by Clostridium perfringens. PLoS Pathog 2008, 2:e26

68. Gileadi O, Burgess-Brown NA, Colebrook SM, Berridge G, Savitsky P, Smee CE, Loppnau P, Johansson C, Salah E, Pantic NH: High throughput production of recombinant human proteins for crystallography. Methods Mol Biol 2008, 426:221-246.

69. Vernet $E$, Kotzsch A, Voldborg B, Sundström M: Screening of genetic parameters for soluble protein expression in Escherichia coli. Protein Expr Purif 2011, 77:104-111.

70. Gasteiger E, Hoogland C, Gattiker A, Duvaud S, Wilkins MR, Appel RD, Bairoch A: Protein identification and analysis tools in the ExPASy server. In The Proteomics Protocols Handbook. Edited by Walker JM. Totowa, NJ: Humana Press; 2005:571-607.

doi:10.1186/s13567-014-0080-0

Cite this article as: Bager et al:: In silico prediction of Gallibacterium anatis pan-immunogens. Veterinary Research 2014 45:80.

\section{Submit your next manuscript to BioMed Central and take full advantage of:}

- Convenient online submission

- Thorough peer review

- No space constraints or color figure charges

- Immediate publication on acceptance

- Inclusion in PubMed, CAS, Scopus and Google Scholar

- Research which is freely available for redistribution

Submit your manuscript at www.biomedcentral.com/submit
C Biomed Central 